\title{
The (Lack of) Influence of Age and Class Standing on Preferred Teaching Behaviors for Online Students
}

\author{
Shannon Kennan and Paula Bigatel \\ Penn State University \\ Susan Stockdale \\ Kennesaw State University \\ Jennifer Hoewe \\ University of Alabama
}

\begin{abstract}
This study contributes to the growing body of literature about what makes a successful online learning environment. Specifically, it addresses assumptions made about online learning environments - regarding self-determination and adult learners - by measuring students' perceptions and preferences for teaching behaviors that they believe help them succeed in online classrooms. Using two waves of survey data, only seven teaching behaviors were consistently related to online learners' preferences based on differences in age and class standing among students, and those behaviors do not fit neatly within the assumptions typically made about adult learners. These findings should begin to raise questions about whether the assumptions made about adult learners actually manifest in online learning environments. This study reveals evidence of a more pragmatically minded group of adult learners, particularly when considering the impact of age and class standing for online students, and provides insight as we look for ways to help online learners be more successful.
\end{abstract}

Keywords: adult learners, self-directed learning, online teaching and learning

Kennan, S., Stockdale, S., Hoewe, J., \& Bigatel, P. (2018). The (lack of) influence of age and class standing on preferred teaching behaviors for online students. Online Learning, 22(1), 163 181. doi:10.24059/olj.v22i1.1086

\section{The (Lack of) Influence of Age and Class Standing on Preferred Teaching Behaviors for Online Students}

Adults - defined as those over the age of 25-are often credited with different learning and learner characteristics than their younger counterparts (Merriam \& Caffarella, 1999). Interestingly, many of the characteristics of adult learners are also cited as positive prerequisites for online learning. It is reasonable to assume this link between effective online learning strategies and adultlearning concepts will continue to grow stronger as more nontraditional adult learners enroll in online coursework. In a previous study (Bigatel et al., 2012), research-based successful online 
teaching behaviors were identified from current best practices in online teaching. Teaching behaviors were defined as the tasks performed during course delivery. Sixty-four unique teaching behaviors were identified, and experienced online faculty and staff were asked to rate their level of importance. Of interest was the fact that over half of the teaching behaviors had a rating of 6.0 or higher on the 7-point scale. Given this, we have proposed that age and class standing (i.e., freshman, sophomore, junior, senior) are positively correlated with those teaching behaviors closely aligned with adult learning theories for online learning. If these hypotheses are substantiated, it would follow that to maximize learning online, instructors and designers need to be cognizant of the age and class standing of online students.

Initially, this study presents an overview of the literature on adult learning and closely aligned theories of motivation, with particular attention paid to online learning and motivation. It then examines specific research findings for success in online learning when age or class standing were used as variables, regardless of the purpose of the investigation. In this study, respondents' age and then class standing were used as independent variables to test their relationships with online students' preferences for particular online teaching behaviors. Several one-way regression models were run to test age and class standing's abilities to predict the importance of each preferred teaching behavior. In this way, the present study will advance knowledge about the ideal teaching practices for online learners, considered through the lens of adult learning theory and selfdetermination theory.

\section{Adults and Learning}

\section{Review of Related Literature}

Andragogy is a formative concept in adult learning and is also referred to as adult education. Malcolm Knowles (1968) is credited with introducing this term into the scholarly literature. Malcolm Knowles (1989) and later Merriam and Brockett (1999) described five relevant assumptions that underlie andragogy: Adults need to know the "why" of what they are asked to learn; adults wish to be treated as capable of directing their own learning (self-direction); adults bring greater life experiences to their learning; adults view learning as a means to inform their immediate real-life situations; and potent motivators for adults are intrinsic (although some extrinsic motivators are important, too). The learning environment also is important. Merriam and Brockett (1997) suggested successful learning takes place when the physical, social, and psychological environment is structured to recognize and support the unique needs of adult learners. Knowles (as cited in Merriam and Caffarella, 1999) suggested the classroom environment "should cause adults to feel accepted, respected, and supported" (p. 273).

Knowles assumed a different pedagogy for children and young adults, as did the work of Perry (1981) and others (e.g., Kasworm, 1983). Perry's work with college students (1981) proposed a nine-stage (with transitions) hierarchical model of understanding or interpreting learning experiences from both a student's and an instructor's view. For example, in Position 1: dualism, the instructor is the authority with the correct answer; if the student does all the work, the faculty member suggests, success will follow. A middle position (Position 5: relativism) is when the student sees all information as relative, and absolutes are few and far between. Perry suggested that this is a powerful stage that allows the learner to think objectively. The student sees that the instructor has expertise but not all the answers; the instructor helps the student by providing resources from which to make reasonable inferences. As the student reaches higher levels, the student reaches "levels of commitment," and he or she is willing to take personal responsibility for 
some areas of his or her life. Within these later stages, personal beliefs and values merge with objective thought. At this point, the faculty member provides choices to allow students to learn what they deem important to learn.

Faculty members can benefit from knowledge about cognitive development theories such as Perry's because cognitive development continues throughout adulthood. They provide an understanding of different stages of cognitive development that inform instructional practices that might more appropriately fit different development stages. Furthermore, the implication for adult learning is that "motivation and readiness to learn will vary according to stage of life-span development" (Knowles, Holton, \& Swanson, 2011, p. 226).

\section{Characteristics of Younger Versus Older Adults and Learning Technology}

More recent literature suggests that young adults (ages 18-24) are often assumed to be more tech savvy. In their review of literature, Bennett, Maton, and Kervin (2008) noted that this group of learners is often described as experiential learners, capable of multitasking, and skilled in communication technologies for retrieving information and having interactions with each other. However, Bennett et al. (2008) noted the lack of research supporting this claim. The authors noted that the research is not as clear as one might expect. These young adults might better be viewed as a heterogeneous group with varying skills and abilities.

A study conducted by Ladyshewsky and Pettapiece (2014) found that adult learners (25 years and older) required additional guidance in the use of technologies such as email, video conferencing, and more media-rich tools, such as Skype and Blackboard Collaborate. This study cautioned instructors that they cannot assume adult learners will use technology appropriately. Furthermore, technology competencies in U.S. adults were found to be below the international average, according to "The Programme for the International Assessment of Adult Competencies" (PIAAC) survey results (Patterson \& Paulson, 2016). Limited technology-related skills can put adult learners at risk when they pursue postsecondary education. Moreover, the NMC Horizon Report states that although millennial students today may be more digitally literate than previous generations because they have been immersed in technology-rich environments, that does not mean they are confident in using technology, especially in an educational context (Johnson et al., p. 24).

\section{Motivation, Adult Learning, and Online Learning}

As inferred earlier when calling attention to the similarities between adult learning characteristics and online learning, motivation (especially intrinsic or self-directed) is often cited as a key to successful online learning. Hartnett, St. George, and Dron (2011) described motivation for online learning as "complex, multifaceted, and situation dependent" (p. 20). However, for purposes of this study, the theory of motivation most closely aligned with adult learning and online learning concepts is Deci and Ryan's (1985) self-determination theory (SDL). Deci and Ryan (2000) suggested that framing motivation within self-determination theory may be a more "psychological meaningful way of defining self-directed learning for purposes of predicting academic achievement, classwork adjustment, and well-being" (p. 75). Within this theory, motivation is situational, and all learners have an intrinsic need for autonomy, competence, and relatedness.

Deci and Ryan (2000) suggested a continuum of levels of motivation defined by perceived levels of learner self-direction and control. They described five stages, ranging from intrinsic motivation (personal enjoyment in the activity and, therefore, self-directedness) at one end of the 
spectrum to amotivational (the learner does not understand the "why" and is nondirected) at the other end. Between these two ends of the continuum are three stages of extrinsic motivation: (1) identified, where the activity is relevant - although perhaps not enjoyable - to the needs of the learner to meet a distal goal and is, therefore, self-controlled; (2) introjected, where activities are completed to meet others' goals and are, therefore, other-directed; and (3) extrinsic, where behaviors are performed for a reward and are other-directed. As students move along the continuum, they become more self-determined and willing to direct their own learning. A study conducted by Rothes, Lemos, and Gonçalves (2017) added that learning strategies that facilitate the "progressive internalization of learners' controlled motivation" also support the continuum idea of self-determination suggested by Deci and Ryan (2000). The authors recommended creating a learning environment that is autonomy-supported, where learners are given choices progressively (Rothes et al., 2017, p. 20). It is understandable that too much autonomy (control) at first may not be a motivating factor given various contextual factors, such as a newness to an online learning environment, length of time away from academic studies, lack of familiarity with course content, and so on. But various research (e.g., Liu, Wang, \& Ryan, 2016; Taylor et al., 2014) has suggested that learning improves as learners move toward more self-determined behaviors.

\section{Online Learning and the SDL Model}

Chen and Jang (2010) investigated a model of motivation in online teaching based on selfdetermination theory (Reeve, 2002). Again, this theory posits autonomy, relatedness, and competency as determinants of self-determination. Motivation itself is viewed on a continuum from amotivation to intrinsic motivation. These authors found support for online learners' needs for autonomy, relatedness, and competency (including fostering peer interactions). Previous studies cited by Chen and Jang (e.g., Reeve, 2002; Reeve \& Jang, 2006) suggested strategies such as allowing choice, providing a rationale for the activities, and offering feedback that supports autonomy and increased self-determination. And as noted, self-determination theory also allows for the consideration of contextual factors that may be important in online learning.

Reeve (as cited in Chen \& Jang, 2010) suggested that instructors need to acknowledge and accept negative responses to the course requirements. Finally, Chen and Jang (2010) called attention to the findings of their course-satisfaction modeling structure that noted "aimless supports without addressing student needs" lead to negative outcomes. Along these lines, Kaul and Lakeym (2003) as well as Reinhardt, Boerner, and Horowitz (2006) presented evidence that there is a real difference in perceived support (perceived valuable by the learner and, therefore, selfdetermined) versus received support (perceived valuable by the other/instructor and, therefore, other controlled and not self-determined). There is a fair amount of literature concerning perceived social support (e.g., in the medical and social work fields) that discusses the impact of perceived versus received support that may also play out in online learning. For example, Helgeson (2006) interviewed 64 patients and their spouses after a cardiac event with the goal of determining which forms of support lead to the best patient adjustments. Results indicated perceived support led to better adjustment than received support. Simply put, received support did not necessarily meet the needs of the individual.

In a related vein, Horzum, Kaymak, and Gungoren (2015) investigated a model that examines the relationships between online readiness, academic motivators, and perceived learning, with more than 400 students. Their hypotheses predicted that increasing learning readiness would increase academic motivation and that increasing academic motivation would directly increase perceived learning. Both hypotheses were supported. For the purposes of this review, it is 
important to note that self-directed learning (SDL) and learner control are the important contributors to higher online-learning readiness levels. When the authors examined academic motivation (citing SDT as the model), intrinsic motivation stood out, accounting for $47 \%$ of the latent variable variance. The authors concluded that "the fact that students encounter interesting or satisfying learning materials seems to be an important component" (Horzum et al., 2015, p. 766).

\section{Age and Perceived Positive Instructor Behaviors}

Ke and Kwak (2013) examined whether online participation, perception, and learning satisfaction remain stable across students' ages. The authors noted that older students spent more time on online activities, with a greater frequency of posting online messages and weekly checking of online messages. However, they also noted the results of an online transcript analysis of the postings, in which older adults did not contribute more meaningful messaging. The authors suggested that older learners may take more time or have difficulties filtering irrelevant information (as a result of cognitive aging). A number of authors have noted that older students spend more time in the online environment (DiBiase \& Kidwai, 2010; Raidal \& Volet, 2004). Northrup (2002) suggested that older students may prefer an experience similar to that of a traditional classroom experience.

Age has been considered by a number of authors using the Community of Inquiry (CoI) model (Garrison, Anderson, \& Archer, 2000, 2010), and a significant body of research has been conducted on this model (Garrison \& Arbaugh, 2007). This model has described an ideal online educational experience with cognitive (interaction with content), social (interaction with peers), and teaching components (interaction with instructor). Within this model, learning occurs from constructing personal meaning in a social process, and age is one of the demographic variables examined in this research. Generally, no differences were found based on age, but Akoyol, Ice, Garrison, and Mitchell (2010) discovered that young adults and elderly individuals perceived the cognitive (interaction with content) and teaching (interaction with instructor) components as one.

Within the above framework, if the object of an online class is to develop a community of inquiry, then the assumption is that one is operating at the higher levels described in Perry's (1981) model. Garrison (2011) suggested a CoI is "a group of individuals who collaboratively engage in purposeful critical discourse and reflection to construct personal meaning and confirm mutual understanding" (p. 15). Three interdependent elements are necessary for learning, and in all three areas the emphasis is on the personal construction of personally meaningful knowledge in a safe community of learners. This type of higher order model appears at odds with Perry's (1981) work with college students, many of whom are at lower levels of cognitive development.

Baturay and Yukselturk (2015) examined the extent that age and other variables accounted for student achievement. Seventy-six percent of the students were young adults in this study. Neither age nor gender were significant predictors of achievement. A linear regression model discovered only the learner's perceived preference for online learning accounted for significant variance in student achievement.

Simonds and Brock (2014) investigated the possible relationship between students' ages and students' preferences for certain types of online learning activities. The researchers grounded their work in the scholarship of teaching and learning (SoTL) model. There was a significant relationship between age and preference for learning activities. Older students were significantly more likely to cite watching videos (prerecorded videos and taped lectures) as a useful tool for learning. These older students carefully took notes from these videos as part of the learning 
experience. Younger students spoke more positively about interactive methods, such as live chats and group projects. Simonds and Brock (2014) suggested that these findings are in line with a 2012 study by Koh and Lim.

\section{Class Standing and Online Learning Instruction}

Ke and Kwak (2013) also found that college education level positively correlated with time-commitment in online learning activities. They also identified a significant correlation between class standing as measured by educational level of undergraduate and graduate level students and the number of online posts/questions concerning course technology or assignment requirements. After interviewing respondents, the authors suggested that undergraduate students viewed online learning as "assignment-test-oriented" - a common pedagogical technique in online courses (p. 49). Students with higher education levels asked for more "dynamic" ways of learning to include "community-like" learning experiences. The authors speculated that students with higher educational levels tended to view web-based distance learning as a positive but less socially fulfilling experience.

Tonsing-Meyer (2013) asked graduate students about their preferences for online practices in relationship to what the authors termed the "instructor's learning activities." Analyses suggested that the read/write learning technique was emphasized in the vast majority of assignments. While the majority of students described their online experiences as positively affecting their learning, they also suggested that authentic interactions - including podcasts, forums, collaborative projects, and video interactions - were important for graduate students' online learning. Students' suggestions also included minimal turnaround time for assignments and timely responses to communications.

Bradford and Wyatt (2010) also examined whether class standing influenced the common elements of student satisfaction, defined as facilitated learning, engagement, and information fluency for online learners. Facilitated learning involved factors related to flexibility, scheduling, and control of learning. Engagement emphasized positive learning opportunities, including more interactions, more collaboration, and better interactions. Information fluency was an increased ability to use and evaluate information. The authors did find a significant effect on scores for facilitated learning (suggesting that higher level students saw more value in flexibility), information fluency, and the engagement dimensions, based on class standing. However, the error values accounted for most of the effect, suggesting class standing may have little influence when compared to other factors that may be at play. Artino (2008) also the emphasized differential support based on students' needs, suggesting undergraduate students may require more explicit support and intermediate assignments than graduate students. Also, the author cited research suggesting the benefit of greater use of self-regulatory strategies when activities are perceived as important or useful.

This study now seeks to examine whether age and/or class standing predict online students' preferred teaching behaviors. The following research questions (RQ) guided our study.

- RQ1: How does age influence students' perceptions of the importance of specific teaching behaviors in an online context?

- RQ2: How does class standing influence students' perceptions of the importance of specific teaching behaviors in an online context? 


\section{Procedure and Respondents}

\section{Methods}

This study included two surveys of students enrolled in online courses. The first survey was completed in the spring and summer semesters of $2014(N=357)$, and the second was conducted during the summer semester of $2015(N=367)$. This study was conducted using responses from two different surveys primarily because the two-study format allowed for comparison between two data sets gathered at two different times. This process increases the reliability of this study's results.

The students who participated in these surveys were recruited from two universities, and each participant was invited to participate in only one of the surveys. One university is a large research institution in the Northeast the other is a mid-sized comprehensive university in the South. The online students included in both samples were diverse in terms of their majors, hailing from numerous fields of study. Respondents were also mostly female (Sample 1: 65.3\%; Sample 2: 66.5\%).

Online instruction during the summer at both of the institutions provides access to surveying the full breadth of online learners because there are many more traditional college students taking online classes while away from campus as well as a strong showing from the university's adult fully online student population. Because of this, we were able to reach all types of students, from traditional 18-year-old first-year students to 50-year-old-and-older adults taking online classes.

Instructors of online courses contacted their students using a recruitment message created by this study's researchers. All instructors were selected based on whether they were listed as the instructor of record for an online course during the semesters considered in this study. The instructors emailed their students, and students then completed the survey by following the link provided in the instructor's email. Respondents first consented to participate and then were asked questions about their perceptions of the importance of online teaching behaviors, multiple demographic variables (including age and class standing), and other items unrelated to the scope of this paper.

\section{Independent Variables}

The first independent variable considered in this study was online students' ages. Respondents' ages in this study ranged from 18 to 66 (Sample 1: 59.4\% were 18-24 years old; Sample 2: 41.1\% were 18-24 years old). In the first survey, age was measured as a grouped variable where respondents selected categories, beginning with 18-24 years old (25-34 years old: $20.7 \%$; 35-41: 14.3\%; 46-55: $4.2 \% ; 56-66: 0.6 \%)$. In the second study, this variable was measured as a continuous variable, where individuals were allowed to select any age, beginning with 18 years old $(M=30.12, S D=10.23)$.

The second independent variable in this study was the student's class standing, which is defined in this study as the level the student has reached based on the number of credit hours they have successfully accumulated (i.e., freshman, sophomore, junior, senior, graduate student). The greatest number of students in both samples identified their class standing as senior (Sample 1: 33.9\%; Sample 2: 32.2\%), but no class standing represented a majority of respondents. Students in both samples were freshmen (Sample 1: 6.2\%; Sample 2: 8.7\%), sophomores (Sample 1: 17.4\%; Sample 2: 13.6\%), juniors (Sample 1: 26.6\%; Sample 2: 28.1\%), and graduate students (Sample 1: 14.8\%; Sample 2: 16.9\%) as well. A very small percentage did not include their class standing (Sample 1: 1.1\%; Sample 2: 0.5\%). As such, the dispersion of class standing across the two samples was consistent. 


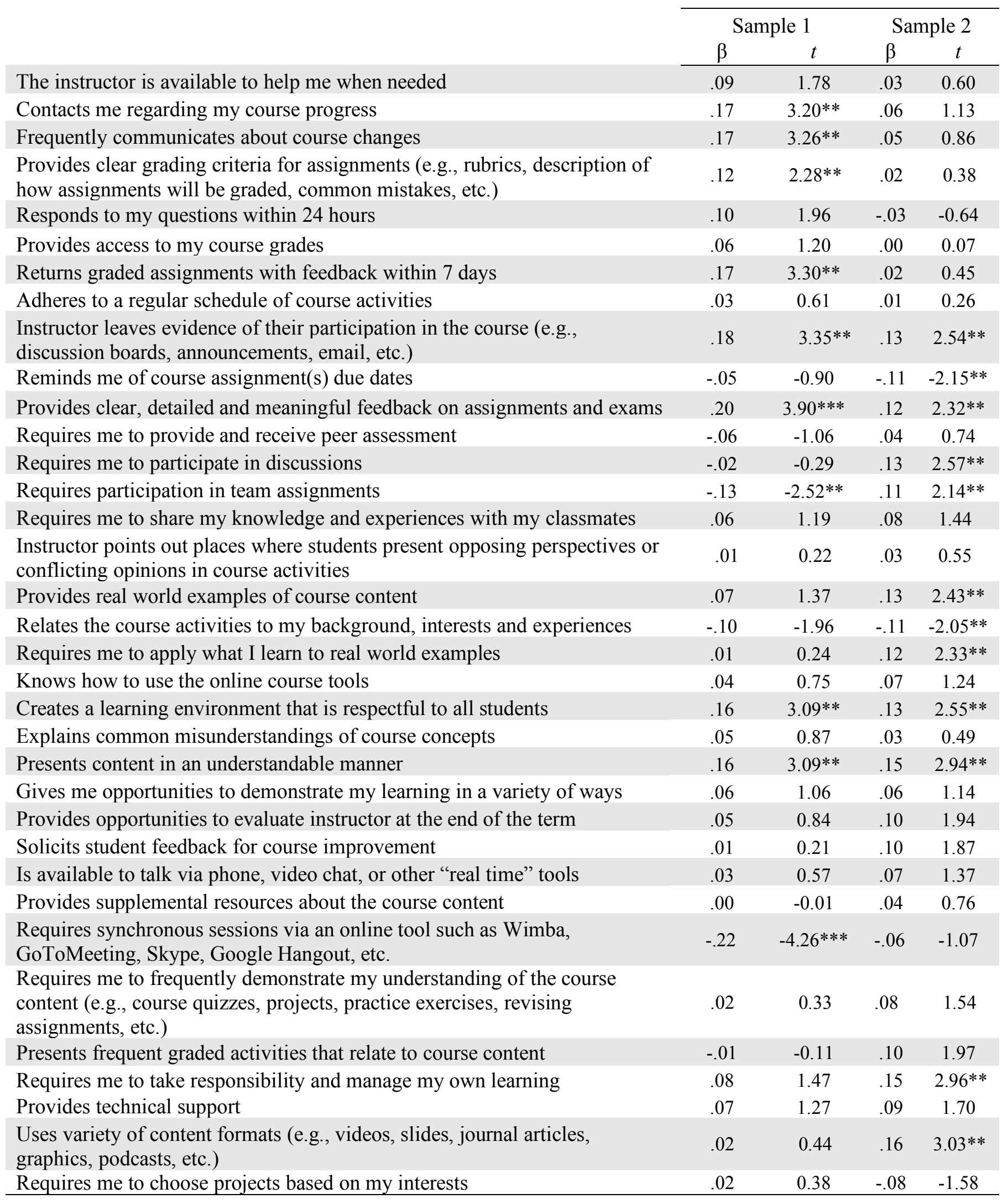

${ }^{* *} p<.05 ; * * * p<.001$

Table 1. Regression Results for Age Predicting Preferred Teaching Behaviors 


\section{Dependent Variables}

The online students included in this study also were asked to rate the importance of 35 teaching behaviors in terms of their ability to facilitate students' online learning, using a scale ranging from 1 (Not at all important) to 5 (Extremely important). These teaching behaviors included 35 statements that asked about the importance of particular teaching behaviors, which were identified through prior research on best practices in online instruction. Based on a previous study, Bigatel, Ragan, Kennan, May, and Redmond (2012) determined the importance of 64 teaching behaviors in online students' learning. The current study utilized the 35 teaching behaviors deemed of greatest importance in Bigatel et al.'s work. Of the 64 teaching behaviors originally tested, more than half $(N=37)$ resulted in a mean score of 6.0 or above on a 7-point scale. Redundant items were removed, resulting in the remaining 35 teaching behaviors examined in this study. (The exact wording of the items is presented in Table 1.)

\section{Results}

To begin, respondents' ages were used as the independent variable. They were used to test this variable's relationship with online students' preferences for particular online teaching behaviors - that is, whether older online students prefer different teaching behaviors than younger adults (i.e., those 18-24 years old). Several one-way regression models were run to test age's ability to predict each teaching behavior. For each sample, this procedure resulted in 35 separate regression models. Table 1 shows the relationships that resulted for both Sample 1 and Sample 2.

The results of these two data sets were then compared to determine similarities across both samples. This analysis strategy was used to ensure that the results provided in this study have proven reliable in two different sets of respondents at two different points in time. It is important to note that there were varying levels of statistical significance across the two samples. However, to more clearly show the consistently significant relationships, Table 2 illustrates when age consistently and significantly predicted online teaching behaviors in Sample 1 and Sample 2.

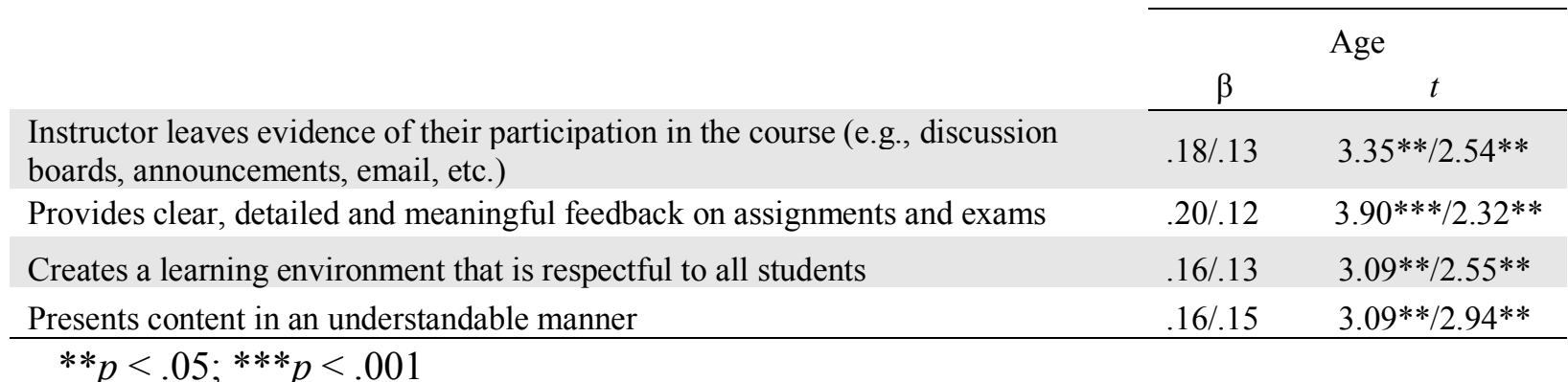

Table 2. Replicated Results: Regression Results for Age Predicting Preferred Teaching Behaviors (Sample 1/Sample 2)

Age consistently predicted four teaching behaviors in both student samples. First, online students who were older found it important that their instructors leave evidence of their participation in the course through discussion board posts, announcements, emails, and so on. Conversely, younger students did not find this evidence of participation to be important. Second, older online students also wanted their instructors to provide clear, detailed, and meaningful feedback on students' assignments and exams, while younger students did not find this important. Third, older online learners found it important that their instructors create a learning environment that was respectful to all students; younger students did not find this respectful environment to be important in their learning. Finally, 
older online students wanted content presented in an understandable manner, whereas younger students did not find it important that content be presented in this way.

The second independent variable - class standing — was then run as the independent variable in regression analyses similar to those previously described. That is, it was used to determine how it predicted online students' preferences for particular online teaching behaviors. Table 3 illustrates the relationships found through these tests.

\begin{tabular}{|c|c|c|c|c|}
\hline & \multicolumn{2}{|c|}{ Sample 1} & \multicolumn{2}{|c|}{ Sample 2} \\
\hline & $\beta$ & $t$ & $\beta$ & $t$ \\
\hline The instructor is available to help me when needed & .02 & 0.28 & -.08 & -1.56 \\
\hline Contacts me regarding my course progress & -.03 & -0.47 & -.09 & -1.80 \\
\hline Frequently communicates about course changes & .02 & 0.44 & -.01 & -0.17 \\
\hline $\begin{array}{l}\text { Provides clear grading criteria for assignments (e.g., rubrics, description of how } \\
\text { assignments will be graded, common mistakes, etc.) }\end{array}$ & -.01 & -0.16 & -.06 & -1.15 \\
\hline Responds to my questions within 24 hours & .02 & 0.43 & -.07 & -1.24 \\
\hline Provides access to my course grades & -.16 & $-2.99 * *$ & -.06 & -1.20 \\
\hline Returns graded assignments with feedback within 7 days & -.09 & -1.68 & .07 & 1.41 \\
\hline Adheres to a regular schedule of course activities & -.06 & -1.13 & -.08 & -1.56 \\
\hline $\begin{array}{l}\text { Instructor leaves evidence of their participation in the course (e.g., discussion boards, } \\
\text { announcements, email, etc.) }\end{array}$ & -.03 & -0.53 & -.03 & -0.62 \\
\hline Reminds me of course assignment(s) due dates & -.16 & $-3.04 * *$ & -.20 & $-3.83 * * *$ \\
\hline Provides clear, detailed and meaningful feedback on assignments and exams & .10 & 1.95 & -.03 & -0.60 \\
\hline Requires me to provide and receive peer assessment & -.07 & -1.25 & .00 & -0.08 \\
\hline Requires me to participate in discussions & .03 & 0.46 & -.01 & -0.14 \\
\hline Requires participation in team assignments & -.04 & -0.73 & .00 & -0.03 \\
\hline Requires me to share my knowledge and experiences with my classmates & .01 & 0.17 & .00 & 0.05 \\
\hline $\begin{array}{l}\text { Instructor points out places where students present opposing perspectives or conflicting } \\
\text { opinions in course activities }\end{array}$ & -.05 & -0.99 & -.04 & -0.78 \\
\hline Provides real world examples of course content & -.04 & -0.74 & .07 & 1.24 \\
\hline Relates the course activities to my background, interests and experiences & -.10 & -1.85 & .04 & 0.71 \\
\hline Requires me to apply what I learn to real world examples & -.05 & -0.96 & .02 & 0.29 \\
\hline Knows how to use the online course tools & .00 & -0.03 & .00 & 0.04 \\
\hline Creates a learning environment that is respectful to all students & -.03 & -0.49 & -.01 & -0.19 \\
\hline Explains common misunderstandings of course concepts & -.08 & -1.55 & -.04 & -0.77 \\
\hline Presents content in an understandable manner & .02 & 0.35 & -.03 & -0.51 \\
\hline Gives me opportunities to demonstrate my learning in a variety of ways & .00 & -0.06 & -.02 & -0.46 \\
\hline Provides opportunities to evaluate instructor at the end of the term & -.03 & -0.59 & -.05 & -0.87 \\
\hline Solicits student feedback for course improvement & -.10 & -1.91 & .01 & 0.13 \\
\hline Is available to talk via phone, video chat, or other "real time" tools & -.18 & $-3.51 * *$ & -.02 & -0.44 \\
\hline Provides supplemental resources about the course content & -.14 & $-2.63 * *$ & -.19 & $-3.64 * * *$ \\
\hline $\begin{array}{l}\text { Requires synchronous sessions via an online tool such as Wimba, GoToMeeting, Skype, } \\
\text { Google Hangout, etc. }\end{array}$ & -.11 & $-2.04 * *$ & -.04 & -0.76 \\
\hline $\begin{array}{l}\text { Requires me to frequently demonstrate my understanding of the course content (e.g., } \\
\text { course quizzes, projects, practice exercises, revising assignments, etc.) }\end{array}$ & -.05 & -0.97 & -.12 & $-2.33^{* *}$ \\
\hline Presents frequent graded activities that relate to course content & -.13 & $-2.39 * *$ & -.14 & $-2.72 * *$ \\
\hline Requires me to take responsibility and manage my own learning & -.06 & -1.05 & -.08 & -1.43 \\
\hline Provides technical support & -.06 & -1.00 & -.11 & $-2.19 * *$ \\
\hline $\begin{array}{l}\text { Uses variety of content formats (e.g., videos, slides, journal articles, graphics, podcasts, } \\
\text { etc.) }\end{array}$ & -.12 & $-2.18 * *$ & -.08 & -1.49 \\
\hline Requires me to choose projects based on my interests & -.07 & -1.23 & -.06 & -1.17 \\
\hline
\end{tabular}

$* * p<.05 ; * * * p<.001$

Table 3. Regression Results for Class Standing Predicting Preferred Teaching Behaviors 
Illustrating the consistently significant results across Sample 1 and Sample 2, Table 4 shows the three teaching behaviors online students found important based on their class standing.

\begin{tabular}{lcc} 
& $\beta$ & $t$ \\
\cline { 2 - 3 } Reminds me of course assignment(s) due dates & $-.16 /-.20$ & $-3.04 * * /-3.83 * * *$ \\
Provides supplemental resources about the course content & $-.14 /-.19$ & $-2.63 * * /-3.64 * * *$ \\
Presents frequent graded activities that relate to course content & $-.13 /-.14$ & $-2.39 * * /-2.72 * *$ \\
\hline$* * p<.05 ; * * * p<.001$ & &
\end{tabular}

Table 4. Replicated Results: Regression Results for Class Standing Predicting Preferred Teaching Behaviors (Sample 1/Sample 2)

First, students with more advanced class standings found it unimportant that their online instructors remind them of assignment due dates. On the other hand, students who weren't as far along in their coursework did find these reminders helpful. Second, online students who reported a higher class standing did not find it important that the instructor provide supplemental resources related to the course content. Students who had earned fewer credits did find these supplemental resources important. Finally, online students who had completed more coursework did not find it helpful when instructors presented frequent graded activities. Students with fewer course credits, however, found it important to have frequent graded activities.

\section{Discussion}

This study contributes to the growing body of literature about what makes a successful online learning environment. Specifically, it addresses assumptions made about online learning environments regarding self-determination and adult learners by measuring students' preferences for teaching behaviors that they believe help them succeed in online classrooms.

Of particular interest for online and adult educators and researchers is how few significant results were found (seven out of 35 teaching behaviors) related to this adult population's preference for particular teaching behaviors based on their ages and class standings. There were only seven teaching behaviors that were consistently related to differences in age and class standing among online students, and those behaviors do not fit neatly within the assumptions typically made about adult learners (Merriam, 2001; Huang, 2002; Ross-Gordon, 2003; Cercone, 2008). Additionally, some teaching behaviors that seem intuitively to fit within the construct of Knowles' adult learning theory (1989) did not register as significant outcomes for this population of adult learners. These findings should begin to raise questions about whether the assumptions made about adult learners actually manifest in online learning environments.

For example, a common assumption made about adult learners is that they like to connect their learning to their real-world life and work experiences (Knowles, 1989; Merriam \& Brockett, 1999). But among the teaching behaviors included in this study, five addressed the connection between the students' real-world life to their coursework (i.e., "requires me to choose projects based on my interests"; "provides real-world examples of course content"; "requires me to apply what I learn to real-world examples"; "relates the course activities to my background, interests, and experiences"; and "requires me to share my knowledge and experiences with my classmates"). Of these five, none were significantly related to adult learners based on age or class standing across both samples. 
Similarly, there were other teaching behaviors that ought to have registered as important to older students because they connect to adult learning theory. However, they did not. For example, Knowles (1989) and Merriam and Brockett's (1999) argument that adults want to feel accepted, respected, and supported seems to logically connect to the following teaching behaviors, but none were predicted by students' ages across both populations: "is available to talk via phone, video chat, or other 'real-time' tools"; "creates a learning environment that is respectful to all students"; "the instructor is available to help me when needed"; "responds to my questions within 24 hours"; "contacts me regarding my course progress"; "frequently communicates about course changes"; "reminds me of course assignment(s) due dates"; and "requires me to take responsibility and manage my own learning." Likewise, Knowles (1989) and Merriam and Brockett's (1999) argument that adults want to be treated as capable of directing their own learning was not reflected in this study's results, as the following teaching behaviors were not significantly predicted by students' ages across both populations: "requires me to take responsibility and manage my own learning"; "solicits student feedback for course improvement"; gives me opportunities to demonstrate my learning in a variety of ways"; and "requires me to choose projects based on my interests."

By contrast, of the three teaching behaviors that were significantly predicted by age across both populations (i.e., "instructor leaves evidence of their participation in the course [e.g., discussion boards, announcements, email, etc.]"; "presents content in an understandable manner"; and "provides clear, detailed and meaningful feedback on assignments and exams"), only the last item connects intuitively to the tenets in adult learning theory. Demonstrating a preference for meaningful feedback is related to adults' preference for knowing why they are being asked to learn certain things (Knowles, 1989; Merriam \& Brockett, 1999) and their desire to feel accepted, respected, and supported in the classroom environment (Merriam \& Caffarella, 1999).

Additionally, Phirangee, Epp, and Hewitt (2016), found evidence that, contrary to assumptions about adult online learners and self-determination theory, graduate students (typically adults) preferred instructor facilitation to provide guidance and support in discussion forums compared to peer-facilitated methods. Furthermore, some studies found that high levels of instructor engagement and ongoing interactions with online students led to deeper and more critical thinking along with confidence in the safety of the learning environment, which resulted in successful learning (Agosto, Copeland, \& Zach, 2013; Dzubinski, 2014; Zach \& Agosto, 2009).

When this study's significant results are examined using Perry's theory of cognitive development (1981), the results are also counterintuitive. For example, all three of the significant teaching behaviors could connect to Perry's lower levels of development (e.g., dualism), where the instructor is viewed as the authority with all of the answers. This seems counterintuitive to the assumption that cognitive development progresses with age, experience, and time (Blimling, 2008; Kitchener et al., 1989), and one might expect to see older learners preferring teaching behaviors that reflect multiplistic, relativistic, and/or committed worldviews and teaching practices (Hood \& Deopere, 2002). However, Hood and Deopere (2002) also found a pattern of more dualistic thinking among the older adults. Backward transition to lower levels of cognitive development has been observed (Fischer et al., 2003) and might apply to adults encountering challenging material or a new learning method or environment.

The dualism characterized in Perry's cognitive development theory may not adequately explain what appears to be a regression in cognitive development. Research literature supports the premise that adults are practical and oriented toward problem-solving behaviors (Merriam, 2001). 
Both characteristics of being practical and oriented toward problem-solving may play out in ways that look like deferring to the instructor as the ultimate authority. Instead, the intention may be different: Practical, problem-solving adult learners may actually be using an interim strategy for coping with the uncertainty of a new learning environment (i.e., online) given that many adult learners are returning to a learning experience that may be vastly different from the one they left. Knowles, Holton, and Swanson (2011) assert that one of the foundations of the adult learning process is that adult learners determine what they need in order to learn so as to achieve their goals. Thus, what adults may need, at times, is to listen to an "expert" and orient themselves to the new learning environment. Furthermore, the teaching approaches many adults were accustomed to have vastly changed with the advent of learner-centered teaching, which more appropriately suits the online environment (Anderson, 2008; Harasim, 2000).

Moreover, the practical side of many adults may dictate that they step back from the need to control their own learning process in the interest of saving precious time for competing obligations (Park \& Choi, 2009). Deferring to the instructor's authority might be a strategy to avoid wasting time and to achieve the learning outcomes more efficiently.

The assumption that all adults have full capacity to direct their own learning and exercise personal autonomy in every learning situation is generally not accepted (Knowles, Holton, \& Swanson, 2011). Grow (1991) suggested that SDL is situational and that the instructor's job is to match their teaching approaches to where the learner is within one of four stages. This model of the instructor attempting to match their teaching strategies to the needs of the learner is exactly the point of this research project: that adaptive teaching behaviors can be utilized to create a more learner-centered online classroom which could, in turn, lead to greater student satisfaction and higher levels of achievement.

\begin{tabular}{llll}
\hline Stage & Learner & Instructor & Examples \\
Stage 1 & Dependent & Authority, coach & $\begin{array}{l}\text { Coaching, frequent feedback, prompts, } \\
\text { informational lectures; efforts at overcoming } \\
\text { deficiencies and/or resistance }\end{array}$ \\
Stage 2 & Interested & Motivator, guide & $\begin{array}{l}\text { Inspiring lectures plus guided discussions; } \\
\text { guided goal-setting and learning strategies }\end{array}$ \\
Stage 3 & Involved & Facilitator & $\begin{array}{l}\text { Instructor-facilitated discussions where instructor } \\
\text { participates as an equal; seminar settings, group } \\
\text { projects. }\end{array}$ \\
Stage 4 & Self-directed & $\begin{array}{l}\text { Consultant, } \\
\text { delegator }\end{array}$ & \begin{tabular}{l} 
study groups. \\
\hline
\end{tabular}
\end{tabular}

Table 5. Grow's Stages in Learning Autonomy

Pratt's (1998) four-quadrant model of high and low direction and support (affective encouragement) provides some explanation for variability in how much direction and instructor involvement is needed. In a given online class, one could encounter some learners who need a great deal of direction and emotional support (Quadrant 1), some that need direction but not much support (Quadrant 2), some who may act like they need support (Quadrant 3), and finally, some who prefer a true andragogical approach (Quadrant 4). To further complicate the picture, those same people may switch quadrants when learning different subject matter. Thus, contextual variables influence the assumptions we make about the behaviors of adult learners. 
This study's significant results related to class standing are simpler to understand overall. It makes intuitive sense that students with higher class standings indicated they did not need reminders about course due dates while students with lower class standings did. Students with lower class standings might naturally want more scaffolding to successfully navigate the course. This might be especially relevant given that many students with lower class standings might be new to the institution, major, and/or the online learning environment all at the same time. But if this is true, it doesn't explain why other teaching behaviors that speak directly to learning support were not significantly predicted by online students' class standing. For example, class standing significantly predicted the importance of due-date reminders, but communicating changes to the course, being available to talk synchronously when needed, and responding quickly to questions were not significant outcomes.

Relatedly, students with higher class standings did not think frequent graded activities or supplemental resources were important, while students with lower class standings did. This result could speak to students' levels of comfort and confidence in their abilities to perform successfully. For example, as above, lower level students who are new to online learning, an institution, or a major might feel unsure about how they are performing. Frequent graded activities give these students multiple opportunities to check on their progress and gauge their performance, and supplemental resources might provide them with alternative ways to grasp course content.

\section{Limitations and Future Research}

Among this study's limitations is the fact that the first sample of online students did not see this survey's question groupings in random order. However, the second survey did randomize the questions. Though there is a possibility that the first survey's results are subject to response bias, the second sample eliminated this potential confound.

In addition, recruiting both samples from students taking online classes in the summer ensured a wide variety of students in the population, but there is no way to know whether the results might have been different with samples from fall and spring semesters. Finally, every effort was made to recruit students from as many academic disciplines as possible, but because the respondents were anonymous, there is no way of knowing if this was achieved.

Future research should focus on using online student samples from various universities in the United States from both fall and spring semesters. These replications should determine whether the results are consistent and reliable or whether the prior theoretical premises need to be revised based on the newer, online learning environment.

The list of teaching behaviors included in the survey is not exhaustive. It was limited to 35 teaching behaviors in order to avoid survey fatigue. Future research could involve a more comprehensive list in order to further delimit which teaching behaviors are effective for which students.

\section{Conclusions}

Retention is an ongoing concern for institutions offering online programs. As the number of online students increases, the demographic variables, learning preparation, confidence levels, and available time and commitment levels become more diversified. This research takes a first step toward addressing specific things online instructors can do to support individual students in their courses. Rather than following the formulaic teaching methods exemplified by the "sage on 
the stage" lecture format, the more ability an instructor has to individualize their teaching and support methods, we believe, the more successful online students can be. Theoretically, instructors could administer a survey with the teaching behaviors in their classes and have an intervention guide of sorts to consult when they notice students are beginning to struggle. Future research by this team will attempt to build upon these strategies.

Recent work examining students' motivations for completing their education online might speak to many of the results found in this study. For example, Donaldson (1993) found that adult learners in online programs had very pragmatic motivations for their education. They placed higher value on working through the degree as simply and cleanly as possible, which may resonate as a "don't waste my time" attitude and may trump other learning theories (Donaldson, 1993). Taken together, the results presented here concerning students' ages seem to speak to this more utilitarian mindset; adult learners might say, "Give me the content in an organized manner, show me that you're in the course with me, and give me meaningful feedback."

If this is the case, it raises the question of whether online instructors need to consider more practical considerations in online pedagogy and instructional design. In some ways, this is a lesson already learned by institutions that offer faster paths to degree completion and shorter but more intensive courses (Choitz \& Printz, 2008; Kucsera \& Zimmaro, 2010). It might also be said to be in direct contradiction with what higher education has traditionally valued: depth and breadth of knowledge. Within this argument, the shadow of the debate about the value of the liberal arts education and the humanities versus a more professional, career-oriented approach to higher education also lurks. While this study did not reveal the results expected to be found in more traditional classrooms, viewed through accepted lenses such as adult learning theory and cognitive development theory, it did reveal evidence of a more pragmatic group of adult learners, particularly when considering the impact of age and class standing for online students. 


\section{References}

Agosto, D. E., Copeland, A. J., \& Zach, L. (2013). Testing the benefits of blended education: Using social technology to foster collaboration and knowledge sharing in face-to-face LIS courses. Journal of Education for Library and Information Science, 54(2), 94.

Akyol, Z., Ice, P., Garrison, R., \& Mitchell, R. (2010). The relationship between course socioepistemological orientations and student perceptions of community of inquiry. The Internet and Higher Education, 13(1-2), 66-68.

Anderson, T. (2008). Theory \& practice of online learning (2nd ed.). New York: Athabasca University Press.

Artino, A. R. (2008). Motivational beliefs and perceptions of instructional quality: Predicting satisfaction with online training. Journal of Computer Assisted Learning, 24(3), 260-270.

Baturay, M. H., \& Yukselturk, E. (2015). The role of online education preferences on student's achievement. Turkish Online Journal of Distance Education-TOJDE, 16(3), 3-13.

Bennett, S., Kervin, L., \& Maton, K. (2008). The “digital natives" debate: A critical review of the evidence. British Journal of Educational Technology, 39(5), 775-786.

Bigatel, P. M., Ragan, L. C., Kennan, S., May, J., \& Redmond, B. F. (2012). The identification of competencies for online teaching success. Journal of Asynchronous Learning Networks, 16(1), 59-77.

Blimling, G. (2010). The resident assistant (7th ed.). Dubuque, IA: Kendall Hunt Publishing.

Bradford, G., \& Wyatt, S. (2010). Online learning and student satisfaction: Academic standing, ethnicity and their influence on facilitated learning, engagement, and information fluency. Internet and Higher Education, 13(3), 108-114.

Cercone, K. (2008). Characteristics of adult learners with implications for online learning design. AACE Journal, 16(2), 137-159.

Chen, K. C., \& Jang, S. J. (2010). Motivation in online learning: Testing a model of selfdetermination theory. Computers in Human Behavior, 26(4), 741-752.

Choitz, V., \& Prince, H. (2008). Flexible learning options for adult students. U.S. Department of Labor Employment and Training Administration.

Deci, E. L., \& Ryan, R. M. (1985). The general causality orientations scale: Self-determination in personality. Journal of Research in Personality, 19, 109-134.

Deci, E. L., \& Ryan, R. M. (2000). The "what" and "why" of goal pursuits: Human needs and the self-determination of behavior. Psychological Inquiry, 11(4), 227-268.

Deci, E. L., \& Ryan, R. M. (2002). Handbook of self-determination research. University Rochester Press.

Dibiase, D., \& Kidwai, K. (2010). Wasted on the young? Comparing the performance and attitudes of younger and older US adults in an online class on geographic information. Journal of Geography in Higher Education, 34(3), 299-326. 
Donaldson, J. (1993). A triangulated study comparing adult college students' perceptions of effective teaching with those of traditional students. Continuing Higher Education Review, $57(3), 147-165$.

Dzubinski, L. (2014). Teaching presence: Co-creating a multi-national online learning community in an asynchronous classroom. Online Learning Journal, 18(2).

Garrison, D. R. (2011). E-Learning in the 21st century: A framework for research and practice. New York, NY: Routledge.

Garrison, D., Anderson, T., \& Archer, W. (2000). Critical inquiry in a text-based environment: computer conferencing in higher education. The Internet and Higher Education, 2-3, 87105.

Garrison, D. R., Anderson, T., \& Archer, W. (2010). The first decade of the community of inquiry framework: A retrospective. The Internet and Higher Education, 13(1-2), 5-9.

Grow, G. O. (1991). Teaching learners to be self-directed. Adult Education Quarterly, 41, 125149.

Harasim, L. (2000). Shift happens: Online education as a new paradigm in learning. The Internet and Higher Education, 3, 41-61.

Hartnett, M., George, A. S., \& Dron, J. (2011). Examining motivation in online distance learning environments: Complex, multifaceted, and situation-dependent. Review: Literature and Arts of the Americas, 12(6), 1-11.

Helgeson, V., Lepore, S. J., \& Eton, D. (2006). Moderators of the benefits of psychoeducational interventions for men with prostate cancer. Health Psychology, 25(3), 348-354.

Hood, A., \& Deopere, D. (2002). The relationship of cognitive development to age, when education and intelligence are controlled for. Journal of Adult Development, 9(3), 229-234.

Horzum, M. B., Kaymak, Z. D., \& Gungoren, O. C. (2015). Structural equation modeling towards online learning readiness, academic motivations, and perceived learning. Kuram ve Uygulamada Egitim Bilimleri, 15(3), 759-770.

Huang, H.-M. (2002). Toward constructivism for adult learners. British Journal of Educational Technology, 33(1), 27-37.

Johnson, L., Adams Becker, S., Cummins, M., Estrada, V., Freeman, A., \& Hall, C. (2016). The NMC horizon report: 2016 higher education edition. Retrieved from https://www.nmc.org/publication/nmc-horizon-report-2016-higher-education-edition/

Kasworm, C. E. (1983). An examination of self-directed contract learning as an instructional strategy. Innovative Higher Education, 8(1), 45-54.

Kaul, M., \& Lakey, B. (2003). Where is the support in perceived support? The role of generic relationship satisfaction and enacted support in perceived support's relation to low distress. Journal of Social and Clinical Psychology, 22(1), 59-78.

Ke, F., \& Kwak, D. (2013). Online learning across ethnicity and age: A study on learning interaction participation, perception, and learning satisfaction. Computers and Education, $61,43-51$. 
Kitchener, K., King, P., Wood, P., \& Davison, M. (1989). Sequentiality and consistency in the development of reflective judgment: A six-year longitudinal study. Journal of Applied Developmental Psychology, 10, 73-95.

Knowles, M. (1989). The making of an adult educator. Toronto: University of Toronto Press.

Knowles, M. S. (1968). Andragogy, not pedagogy. Adult Leadership, 16(10), 350-352.

Knowles, M. S., Holton, E. F., \& Swanson, R. A. (2011). The adult learner: The definitive classic in adult education and human resource development (7th ed.). Burlington, MA: Elsevier.

Koh, E., \& Lim, J. (2012). Using online collaboration applications for group assignments: The interplay between design and human characteristics. Computers and Education, 59(2), 481496.

Kucsero, J. V., \& Zimmaro, D. M. (2010). Comparing the effectiveness of intensive and traditional courses. College Teaching, 58(2), 62-68.

Ladyshewsky, R., \&, Pettapiece, R. G. (2014). Exploring adult learners usage of information communication technology during a virtual peer coaching experience. Online Learning, 19(2), 1-15.

Merriam, S. (2001). Andragogy and self-directed learning: Pillars of adult learning theory. New Directions for Adult and Continuing Education, 89, 3-13.

Merriam, S. B., \& Brockett, R. G. (1997). The profession and practice of adult education: An introduction. San Francisco: Jossey-Bass.

Merriam, S., \& Caffarella, R. (1999). Key theories of learning. In Learning in adulthood: A comprehensive guide (pp. 248-256). San Francisco: Jossey-Bass.

Northrup, P. T. (2002). Online learners' preferences for interaction. Quarterly Review of Distance Education, 3(2), 219-226.

Park, J., \& Choi, H. J. (2009). Factors influencing adult learners' decision to drop out or persist in online learning. Journal of Educational Technology \& Society, 12(4), 207-217.

Patterson, M. B., \& Paulson, U. G. (2016). Adult transitions to learning in the USA: What do PIAAC survey results tell us? Journal of Research and Practice for Adult Literacy, Secondary, and Basic Education, 5(1) 5-27.

Perry, W. G. (1981). Cognitive and ethical growth: The making of meaning. In The modern American college: Responding to the new realities of diverse students and a changing society. San Francisco: Jossey-Bass.

Phirangee, K., Demmans Epp, C., \& Hewitt, J. (2016). Exploring the relationships between facilitation methods, students' sense of community, and their online behaviors. Online Learning Journal, 20(2).

Pratt, D. D. (1988). Andragogy as a relational construct. Adult Education Quarterly, 38, 160181.

Raidal, S. L., \& Volet, S. E. (2009). Preclinical students' predispositions towards social forms of instruction and self-directed learning: A challenge for the development of autonomous and collaborative learners. Higher Education, 57(5), 577-596. 
Reeve, J. (2002). Self-determination theory applied to educational settings. In E. L. Deci \& R. M. Ryan, Handbook of self-determination research (pp. 183-203). Rochester, NY: University of Rochester Press.

Reeve, J., \& Jang, H. (2006). What teachers say and do to support students' autonomy during a learning activity. Journal of Educational Psychology, 98(1), 209-218.

Reinhardt, J. P., Boerner, K., \& Horowitz, A. (2006). Good to have but not to use: Differential impact of perceived and received support on well-being. Journal of Social and Personal Relationships, 23(1), 117-129.

Ross-Gordon, J. (2003). Adult learners in the classroom. New Directions for Student Services, $102,43-52$.

Rothes, A., Lemos, M. S., \& Gonçalves, T. (2017). Motivational profiles of adult learners. Adult Education Quarterly, 61(1) 3-29.

Simonds, T. A., \& Brock, B. L. (2014). Relationship between age, experience, and student preference for types of learning activities in online courses. Journal of Educators Online, 11(1) $1-19$.

Taylor, G., Jungert, T., Mageau, G. A., Schattke, K., Dedic, H., Rosenfield, S., \& Koestner, R. (2014). A self-determination theory approach to predicting school achievement over time: The unique role of intrinsic motivation. Contemporary Educational Psychology, 39(4), $342-358$.

Tonsing-Meyer, J. A. (2012). An examination of online instructional practices based on the learning styles of graduate education students. Quarterly Review of Distance Education, 14(3), 141-149.

Zach, L., \& Agosto, D. E. (2009). Using the online learning environment to develop real-life collaboration and knowledge-sharing skills: A theoretical discussion and framework for online course design. Journal of Online Learning and Teaching, 5(4), 590. 